\title{
Diversidade genética de Parkia pendula (Willd.) Benth. Ex Walp. nativa na Amazônia
}

\section{Matogrossense}

\author{
Genetic diversity of Parkia pendula (Willd.) Benth. Ex Walp. native in Amazonia Matogrossense \\ Diversidad genética de Parkia pendula (Willd.) Benth. Ex Walp. nativo en Amazon Matogrossense
}

Recebido: 19/04/2021 | Revisado: 26/04/2021 | Aceito: 30/04/2021 | Publicado: 15/05/2021

\author{
Anne Sthephane Arrolho Silva Correa \\ ORCID: https://orcid.org/0000-0003-0356-7830 \\ Igarapés Consultoria Socioambiental, Brasil \\ E-mail: anne.correa@unemat.br \\ Petterson Baptista da Luz \\ ORCID: https://orcid.org/0000-0003-4067-0087 \\ Universidade do Estado de Mato Grosso, Brasil \\ E-mail: petterson@unemat.br \\ Ana Aparecida Bandini Rossi \\ ORCID: https://orcid.org/0000-0002-8318-5375 \\ Universidade do Estado de Mato Grosso, Brasil \\ E-mail: anabanrossi@unemat.br \\ Beatriz Fernanda Silva Lima \\ ORCID: https://orcid.org/0000-0003-2983-6963 \\ Universidade do Estado de Mato Grosso, Brasil \\ E-mail: beatrizfernanda_lima@hotmail.com \\ Solange Aparecida Arrolho da Silva \\ ORCID: https://orcid.org/0000-0002-8038-1303 \\ Universidade do Estado de Mato Grosso, Brasil \\ E-mail:solange.arrolho@unemat.br
}

\begin{abstract}
Resumo
Este estudo objetivou estimar a diversidade genética entre matrizes de Parkia pendula (Will.) Benth. Ex Walp. nativa na Amazônia Matogrossense, com base nas características fisiológicas das sementes. Para caracterização da semente foi empregados o teste de germinação, índice de velocidade de germinação, Teste de condutividade elétrica e Teste de envelhecimento acelerado em delineamento inteiramente casualizado com quatro repetições de 25 sementes. Para realização do teste de germinação, as sementes foram submetidas a um procedimento para superação de dormência, onde as sementes foram imersas em Ácido Sulfúrico a 98\% durante 30 minutos. Por meio do método de agrupamento das médias, averiguou-se que a matriz 15 apresentou os maiores valores para índice de velocidade de germinação $(19,20)$ e porcentagem de germinação $(100 \%)$. As sementes submetidas ao teste de envelhecimento acelerado apresentaram os melhores resultados para índice de velocidade germinação nas matrizes 1,3, 4, 7, 10,18, 24, 27,29 e 30 e as matrizes $2,4,6,7,8,9,10,12,15,16,17,18,20,21,24,26,28$ e 30 com as maiores porcentagens de germinação. Pelo método de otimização de Tocher houve a formação de seis grupos distintos e no dendrograma houve a distinção de $\mathrm{V}$ grupos. Conclui-se com base na população estudada que houve grande diversidade genética para atributos relacionados a características morfofisiológicas das sementes.
\end{abstract}

Palavras-chave: Angelim saia; Vigor de sementes; Espécie florestal.

\begin{abstract}
This study aimed to estimate the genetic divergence between Parkia pendula (Will.) Benth. Ex Walp. native in the Amazon of Mato Grosso, based on the physiological characteristics of the seeds. To characterize the seed, the Germination Test, Germination Speed Index, Electrical Conductivity Test and Accelerated Aging Test in a completely randomized design with four replications of 25 seeds were used. To perform the germination test, the seeds were subjected to a procedure to overcome dormancy, where the seeds were immersed in $98 \%$ sulfuric acid for 30 minutes. Through the method of grouping the averages, it was found that matrix 15 presented the highest values for germination speed index $(19,20)$ and percentage of germination $(100 \%)$. The seeds submitted to the accelerated aging test, presented the best results for germination speed index in matrices 1, 3, 4, 7, 10, 18, 24, 27, 29 and 30 and matrices $2,4,6,7,8,9,10,12,15,16,17,18,20,21,24,26,28$ and 30 with the highest germination percentages. By the Tocher optimization method, six distinct groups were formed and in the dendrogram there was a distinction of $\mathrm{V}$ groups. It is concluded based on the population studied that there was great genetic diversity for attributes related to seed morphophysiological characteristics.
\end{abstract}

Keywords: Angelim edge; Vigor seed; Forest species. 


\begin{abstract}
Resumen
Este estudio tuvo como objetivo estimar la diversidad genética entre Parkia pendula (Will.) Benth. Ex Walp. nativa de la Amazonia Matogrossense, con base en las características fisiológicas de las semillas. Para la caracterización de semillas se utilizó la prueba de germinación, índice de velocidad de germinación, prueba de conductividad eléctrica y prueba de envejecimiento acelerado en un diseño completamente al azar con cuatro repeticiones de 25 semillas. Para realizar la prueba de germinación, las semillas se sometieron a un procedimiento para superar la latencia, donde las semillas se sumergieron en ácido sulfúrico al $98 \%$ durante 30 minutos. Mediante el método de agrupación de los promedios, se encontró que la matriz 15 presentó los valores más altos para índice de velocidad de germinación (19, 20) y porcentaje de germinación (100\%). Las semillas sometidas a la prueba de envejecimiento acelerado mostraron los mejores resultados para índice de velocidad de germinación en las matrices 1,3, 4, 7, 10,18, 24, 27, 29 y 30 y las matrices $2,4,6,7,8,9,10,12,15,16,17,18,20,21,24,26,28$ y 30 con los mayores porcentajes de germinación. Mediante el método de optimización de Tocher, se formaron seis grupos distintos y en el dendrograma había una distinción de $\mathrm{V}$ grupos. Se concluye con base en la población estudiada que existió una gran diversidad genética de atributos relacionados con las características morfofisiológicas de las semillas.
\end{abstract}

Palabras clave: Falda angelim; Vigor de la semilla; Especies forestales.

\title{
1. Introduçãa
}

O gênero Parkia é de distribuição pantropical, com maior diversidade na Amazônia, englobando 17 espécies. Parkia pendula (Willd.) Benth. Ex Walp., conhecida vulgarmente por "visgueiro", é encontrada na região Amazônica, porém na sua distribuição vai do espírito santo a América Central (Souza Filho et al., 2005). Árvore pertencente à família Leguminosae Mimosoideae, considerada perenifólia, mesófita ou heliófita, apresenta cerca de 20 a 50 metros de altura, pertencendo ao grupo ecológico das secundárias (Santana et al., 2018).

Oliveira e Ferraz (2003) afirmou que o conhecimento da germinação, do crescimento e do estabelecimento da plântula é imprescindível na compreensão do ciclo biológico e da regeneração natural das espécies. As análises da germinação, dentre outras, possuem uma finalidade de oferecer informações sobre a qualidade fisiológica das sementes. A capacidade de germinação e produção de plântulas normais depende da qualidade das sementes, sendo avaliadas pelos testes germinativos, os quais agregam valores no uso tanto na semeadura como no armazenamento e distribuição comercial (Schumacher et al., 2002). Fisiologicamente, este é um processo biológico que engloba grande número das reações químicas, das quais compostos orgânicos presentes nas sementes são desdobrados e reorganizados de tal maneira, que se permite o desenvolvimento do eixo embrionário. Algumas sementes, embora viáveis, não germinam em condições propícias, sendo, portanto, consideradas dormentes (Malavasi, 1988).

Carvalho e Nakagawa (2012) consideram a dormência como recurso pelo qual a natureza distribuía germinação das sementes no tempo. No entanto, para Rodrigues (2020) em espécies florestais nativas normalmente a germinação é baixa e heterogênea, além de precisarem de um tempo maior para a sua germinação.

Assim, o presente trabalho foi desenvolvido com o objetivo de estimar a diversidade genética entre as matrizes de Parkia pendula espécie nativa ocorrente na Amazônia Matogrossense, com base nas características fisiológicas de sementes.

\section{Metodologia}

A área de amostragem foi a região Norte do Estado de Mato Grosso, compreendendo a coleta de frutos e sementes das matrizes de Parkia pendula em 30 pontos (Figura 1), com ocorrência nos Municípios de Alta Floresta, Carlinda, Nova bandeirantes Nova Canaã do Norte, Colíder, Itaúba e Sinop. 
Figura 1 - Imagem de satélite dos municípios e pontos amostrais das matrizes de Parkia pendula na Amazônia Matogrossense.

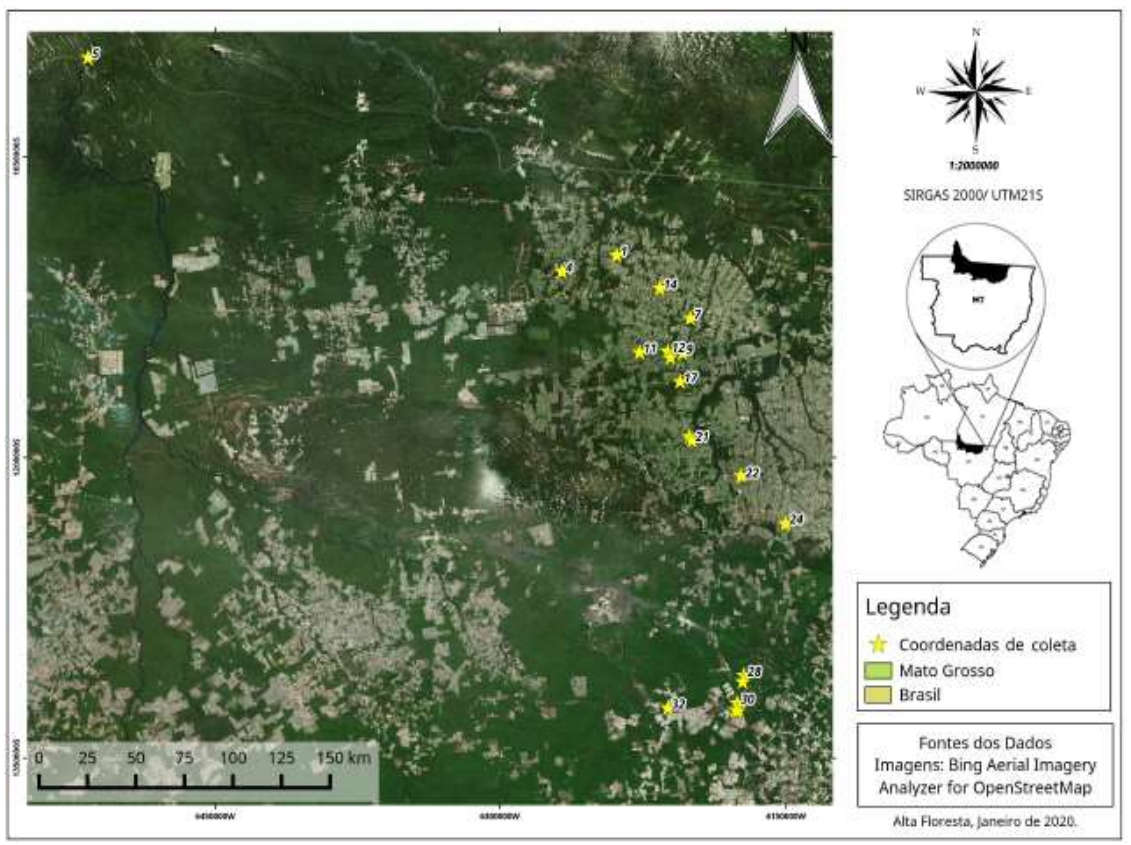

Fonte: Autores.

A vegetação do local é do tipo Floresta Estacional Semidecidual com enclaves de Floresta Ombrófila Aberta contida na região amazônica. O clima pode ser caracterizado como tropical de savana (Aw), segundo a classificação climática de Köppen, e possui duas estações climáticas bem definidas: chuvosa (outono a abril) e a seca (maio a setembro), com temperatura média anual de $24^{\circ} \mathrm{C}$ e precipitação total anual variando de 1200 a $2000 \mathrm{~mm}^{\text {ano }}{ }^{-1}$ (Pieper, 2020).

Foram identificadas 30 árvores matrizes em pontos de ocorrência natural com plena produção de frutos e sementes. Os frutos de Parkia pendula foram colhidos com auxílio de tesoura de poda alta (podão), estilingues com linha de pesca $\mathrm{n}^{\circ}$ 0,60 e chumbada amarrada na ponta no período de agosto a setembro de 2019. Após a colheita os frutos, foram acondicionados em sacos plásticos, devidamente identificados os pontos de coleta e das respectivas matrizes, tomando as coordenadas geográficas e transportado ate o Laboratório Vegetal - Universidade do Estado de Mato Grosso, Alta Floresta.

Em laboratório os frutos foram beneficiados, retirando toda serapilheira agregada a resina dos que se encontravam no solo, os mesmos foram abertos e retiradas as sementes de boa qualidade que não apresentavam ataques de coleópteros (Acanthoscelides imitator), e armazenadas em sacos de papel de tamanho 5x24cm. Posteriormente o material foi encaminhado ao Laboratório de Sementes e Plantas Ornamentais do Campus da UNEMAT de Cáceres-MT, para a realização dos testes nas sementes coletadas.

Para caracterização da semente foram empregados o teste de germinação (GERM), índice de velocidade de germinação (IVG), Teste de condutividade elétrica (CONDUT) e Teste de envelhecimento acelerado (ENV) em delineamento inteiramente casualizado com quatro repetições de 25 sementes.

Para o teste de germinação, inicialmente quantificou-se o Teor de água das sementes, para assegurar que este não interferiria no resultado. Outra medida tomada foi à assepsia da semente em solução de álcool 70\% (v/v) durante 1 minuto, e em hipoclorito de sódio (2,5\% de cloro ativo) por 5 minutos, sendo por fim lavada em água destilada.

Foi determinado o Teor de água das sementes, através do método da estufa a $105^{\circ} \mathrm{C} \pm 3^{\circ} \mathrm{C}$, durante 24 horas, onde se avaliou o peso das sementes úmidas e posteriormente o peso das sementes secas, conforme prescrição das Regras para Análise de Sementes (BRASIL, 2009). Foram utilizadas duas repetições de 20 sementes para cada matriz, onde foram mantidas 24 
horas em uma estufa de circulação forçada e, posteriormente em dessecadores com sílica em gel durante 10 minutos para realização da pesagem das sementes secas.

Para o cálculo da porcentagem de umidade, foi utilizada a seguinte equação: \% de Umidade (U) $=100 \mathrm{x}$ (Peso inicial - peso final)/Peso inicial - tara do recipiente.

Para realização do teste de germinação, as sementes foram submetidas a um procedimento para superação de dormência, sendo imersas em Ácido Sulfúrico a 98\% durante 30 minutos (Matias et al., 2019). Posteriormente todas as sementes foram lavadas em água corrente com auxílio de peneira de metal para que não houvesse corrosão.

No teste de germinação, foram utilizadas quatro repetições de 25 sementes para cada planta matriz. As sementes foram alocadas em caixas de acrílico (“Gerbox”) transparentes, sobre duas folhas de papel mata borrão, umedecidas com água destilada na proporção de duas vezes e meia o peso do papel. Para manutenção da umidade, as caixas foram colocadas em sacos de polietileno transparente e levadas para câmara de germinação com temperatura constante de $30^{\circ} \mathrm{C}$, e fotoperíodo de 12 h, até o final do experimento, aos 20 dias de acordo com procedimento adotado por Brasil (2009).

A contagem das sementes germinadas deu início ao terceiro dia após a implantação do teste, onde foram avaliadas germinadas as sementes que apresentaram raiz primária com no mínimo $5 \mathrm{~mm}$ de comprimento.

Seguindo a metodologia de Brasil (2009), prescrita para o teste de germinação, foi avaliado o índice de velocidade de germinação. Para isso o monitoramento foi realizado diariamente e sempre no mesmo horário, considerando-se germinada a semente que rompesse o tegumento e emitisse radícula com pelo menos $5 \mathrm{~mm}$ de comprimento. As avaliações foram realizadas até o momento da última contagem, e o cálculo do índice de velocidade de germinação foi efetuado conforme Maguire (1962).

Para o teste de condutividade elétrica (CE) foram realizadas 4 repetições de 25 sementes para cada matriz, as quais foram previamente pesadas em balança analítica com precisão de 0,001 g. Cada repetição foi acondicionada em copo de plástico $(250 \mathrm{ml})$ contendo $75 \mathrm{ml}$ de água deionizada, e, posteriormente, submetida a 2 e 4 horas de embebição. Para cada período foi aferida a leitura de CE na solução de embebição das sementes usando condutivímetro de bancada. $\mathrm{O}$ valor de cada leitura foi dividido pela respectiva massa da amostra, expressando-se os resultados de condutividade elétrica em $\mu \mathrm{S} \mathrm{cm}^{-1} \mathrm{~g}^{-1} \mathrm{de}$ semente.

O teste de envelhecimento acelerado foi realizado com sementes das 30 matrizes de Parkia pendula, sendo utilizadas 100 sementes por matriz. As sementes de cada matriz foram acondicionadas em caixas transparentes "GERBOX" contendo 50 $\mathrm{ml}$ de água destilada cada, ficando estas suspensas em grades dentro das caixas para que não houvesse contato e, submetidas a temperatura de $42{ }^{\circ} \mathrm{C}$ durante $48 \mathrm{~h}$ em câmara BOD.

Após a aplicação do teste de envelhecimento acelerado, as sementes de cada matriz foram submetidas ao teste de germinação. Para isto foram utilizadas quatro repetições de 25 sementes, em caixas "GERBOX" com substrato de papel mata borrão umedecido com água destilada na proporção de duas vezes e meia o peso do papel à temperatura de $30^{\circ} \mathrm{C}$. $\mathrm{O}$ teste de germinação foi conduzido por 5 dias, até o período de estagnação da germinação. Avaliou-se diariamente o número de sementes germinadas, adotando-se como critério de germinação a protrusão da radícula com pelo menos $5 \mathrm{~mm}$ de comprimento (Brasil 2009). Ao final do experimento, foi determinado a porcentagem total de sementes germinadas e o índice de velocidade de germinação (IVG).

\subsection{Análise dos Dados}

Primeiramente os dados foram submetidos ao teste de normalidade de Shapiro-Wilk utilizando-se o programa estatístico R versão 2.15.2 (R Core Team, 2012).

Os dados referentes à Porcentagem de Germinação (GERM), Índice de Velocidade de Germinação (IVG), Teste de Condutividade Elétrica (COND) e Teste de Envelhecimento Acelerado (ENV) foram transformados em $\sqrt{x}_{\mathrm{x}}+0,5$ (Royston, 
1983). A interpretação estatística dos dados foi feita por meio da análise de variância e as médias agrupadas pelo teste de Skott-Knott $(\mathrm{P} \leq 0,05)$ utilizando-se o programa Genes (Cruz \& Carneiro, 2006).

A divergência genética entre as matrizes foi avaliada por análises multivariadas, empregando-se como medida de dissimilaridade a distância generalizada de Mahalanobis $\left(\mathrm{D}^{2}{ }_{\mathrm{ii}}{ }^{\prime}\right)$, sendo adotado o critério de que a média das medidas da divergência genética dentro de cada grupo deve ser menor que as distâncias médias entre quaisquer grupos.

Para facilitar a interpretação da medida de dissimilaridade entre as matrizes, utilizou-se os métodos de agrupamento de Otimização de Tocher, UPGMA (Unweighted Pair-Group Method with Arighmetic Average) e análise de Variáveis Canônicas (Cruz \& Regazzi, 2001).

A importância relativa de cada caráter para a divergência genética foi estimada através do método proposto por Sing (1981), o qual se baseia na partição do total das estimativas das distâncias de Mahalanobis $\left(\mathrm{D}^{2}{ }_{\mathrm{ii}}{ }^{*}\right.$ ), considerando todos os possíveis pares de progênies, para as partes devidas a cada caráter (CRUZ et al., 2004). Pelo método do UPGMA, utilizam-se as médias aritméticas (não ponderadas) das medidas de dissimilaridade, evitando assim, caracterizar a dissimilaridade por valores extremos (mínimo e máximo) entre as matrizes consideradas (Cruz \& Regazzi, 2001).

As análises dos métodos de Otimização de Tocher, UPGMA, Variáveis Canônicas e importância relativa dos caracteres pelo método Singh foram realizadas utilizando-se o programa computacional GENES (Cruz \& Carneiro, 2006).

\section{Resultados e Discussão}

De acordo com o método de agrupamento das médias, averiguou-se que a matriz 15 apresentou os maiores valores para índice de velocidade de germinação $(19,20)$ e porcentagem de germinação $(100 \%)$. As demais matrizes também apresentaram valores de porcentagem de germinação acima de 80\%. Já a matriz 29 apresentou o valor mais baixo com $71 \%$ (Tabela 1). Para o IVG formou-se 2 grupos, os maiores IVG $(1,2,3,4,5,6,7,8,9,10,12,13,15,16,17,18,20,21,22,23$, $24,25,27,29)$ e as demais forma menores. Para a porcentagem de germinação formou-se 2 grupos, as maiores porcentagens de germinação foram nas matrizes $2,3,4,6,7,8,9,10,12,15,16,17,18,20,21,24,26,28,30$. Essas matrizes foram coletadas em area umidas, nas bordas das áreas de mata ciliar ocorrendo uma maior absorção de água nos períodos iniciais de frutificação.

Para porcentagem de germinação após o teste de envelhecimento acelerado, o teste de Skott-Knott agrupou as matrizes em três grupos, tanto para o parâmetro IVG, quanto para a porcentagem de germinação. As matrizes 1,3, 4, 7, 10,18, 24, 27, 29 e 30 apresentaram os melhores resultados para IVG e as matrizes 2, 4, 6, 7, 8, 9, 10, 12, 15, 16, 17, 18, 20, 21, 24, 26, 28 e 30 com as maiores porcentagens de germinação. O coeficiente de variação para germinação das sementes após envelhecimento acelerado apresentou 9,28\%, indicando um ótimo controle experimental.

Pode ser observado na Tabela 1 que a germinação das sementes de Parkia pendula diminui após o tempo de envelhecimento acelerado. Esse resultado era esperado, pois, conforme Carvalho e Nakagawa (2012), à medida que ocorre o processo de envelhecimento, a semente vai absorvendo a umidade, ocasionando um acréscimo na temperatura das sementes por conta dos processos respiratórios e do aumento de atividades de fungos presentes nas mesmas; e, consequentemente, diminuindo o vigor e podendo ocasionar a morte.

Para o teste de condutividade elétrica durante duas horas de embebição, com o resultado do teste de Skott-Knott em dois grupos. Um grupo formado pelas matrizes 1, 3, 5, 11, 13, 14 19, 22, 23, 25, 27 e 29 onde apresentaram os valores mais elevados, observa-se que ocorreu uma alta lixiviação de solutos para o meio de embebição, em função da deterioração das sementes das matrizes, contudo as matrizes $2,4,6,7,8,9,10,12,15,16,17,18,20,21,24,26,28$ e 30, foram as que tiveram menor quantidade de lixiviados liberados na solução de embebição (Tabela 1). 
$\mathrm{O}$ grau de umidade médio das 30 matrizes foi de $8,77 \%$. Analisando a Tabela 1, as matrizes que tiveram maior e menor Teor de água foram a 15 e 19, com os respectivos teores de 9,82\% e 7,75\%, porém não diferindo estatisticamente das demais matrizes. A variação do Teor de água das sementes pode indicar uma plasticidade da espécie em função da área de ocorrência delas.

Para o grau de umidade, o teste de Skott-Knott agrupou as matrizes em dois grupos, um formado pelas matrizes 2, 4, $6,7,8,9,10,12,15,16,17,18,19,20,21,24,26,28$ e 30 onde apresentaram os valores mais elevados, contudo as matrizes, $1,3,5,11,13,22,23,25,27$ e 29 apresentaram menor valor no grau de umidade das sementes (Tabela 1).

Os resultados obtidos corroboram com as observações de Camara (2005), onde a espécie Parkia pendula apresenta a sua frutificação nos meses de agosto a setembro, mesmo período da estação seca e de baixa umidade e os resultados do Teor de água das sementes das matrizes do presente trabalho serem abaixo de 10\%. Sementes ortodoxas podem ser mantidas abaixo de $10 \%$ do Teor de água, como também podendo ser armazenadas em temperaturas a $-20^{\circ} \mathrm{C}$, sem que haja comprometimento do vigor e da viabilidade das sementes.

Tabela 1 - Média das 30 matrizes amostradas na Amazônia Matogrossense de Parkia pendula para avaliação das sete variáveis quantitativas de sementes.

\begin{tabular}{|c|c|c|c|c|c|c|c|}
\hline Matrizes & IVG & GERM & IVG-ENV & GERM-ENV & COND 2h & COND $4 \mathrm{~h}$ & $\begin{array}{l}\text { Teor de } \\
\text { água\% }\end{array}$ \\
\hline $1 \mathrm{M}$ & $8,87 \mathrm{~b}$ & $79 \mathrm{~b}$ & $16,96 \mathrm{c}$ & $85 \mathrm{a}$ & $21,44 \mathrm{a}$ & $36,99 \mathrm{a}$ & $7,77 \mathrm{~b}$ \\
\hline $2 \mathrm{M}$ & $15,13 \mathrm{a}$ & $96 \mathrm{a}$ & $18,25 \mathrm{~b}$ & $85 \mathrm{a}$ & $13,94 \mathrm{~b}$ & $45,86 \mathrm{a}$ & $9,27 \mathrm{a}$ \\
\hline $3 \mathrm{M}$ & $10.54 \mathrm{a}$ & $74 \mathrm{~b}$ & $20,23 \mathrm{a}$ & $88 \mathrm{a}$ & $16,94 \mathrm{~b}$ & $29,56 \mathrm{~b}$ & $7,76 \mathrm{~b}$ \\
\hline $4 \mathrm{M}$ & $11,75 \mathrm{a}$ & $93 a$ & $14,41 \mathrm{c}$ & $80 \mathrm{~b}$ & $16,56 \mathrm{~b}$ & $25,91 \mathrm{~b}$ & $9,32 \mathrm{a}$ \\
\hline $5 \mathrm{M}$ & $12,08 \mathrm{a}$ & $78 \mathrm{~b}$ & $14,35 \mathrm{c}$ & $87 a$ & $21,72 \mathrm{a}$ & $29,69 \mathrm{~b}$ & $7,98 \mathrm{~b}$ \\
\hline $6 \mathrm{M}$ & $11,58 \mathrm{a}$ & $94 \mathrm{a}$ & $19,33 \mathrm{~b}$ & $89 a$ & $12,34 \mathrm{~b}$ & $18,92 \mathrm{~b}$ & $9,02 \mathrm{a}$ \\
\hline $7 \mathrm{M}$ & $11,50 \mathrm{a}$ & $91 \mathrm{a}$ & $21,12 \mathrm{a}$ & $93 \mathrm{a}$ & $18,25 \mathrm{~b}$ & $23,96 \mathrm{~b}$ & $9,61 \mathrm{a}$ \\
\hline $8 \mathrm{M}$ & $12,13 \mathrm{a}$ & $97 \mathrm{a}$ & $12,21 \mathrm{~b}$ & $83 \mathrm{~b}$ & $14,10 \mathrm{~b}$ & $32,84 \mathrm{a}$ & $8,29 \mathrm{a}$ \\
\hline $9 \mathrm{M}$ & $11,63 \mathrm{a}$ & $90 \mathrm{a}$ & $19,63 \mathrm{~b}$ & $89 a$ & $18,22 \mathrm{~b}$ & $29,86 \mathrm{~b}$ & $9,23 \mathrm{a}$ \\
\hline $10 \mathrm{M}$ & $14,29 \mathrm{a}$ & $93 \mathrm{a}$ & $20,91 \mathrm{a}$ & $95 \mathrm{a}$ & $16,84 \mathrm{~b}$ & $22,48 \mathrm{~b}$ & $9,16 \mathrm{a}$ \\
\hline $11 \mathrm{M}$ & $8.95 \mathrm{~b}$ & $76 \mathrm{~b}$ & $17,83 \mathrm{~b}$ & $84 \mathrm{~b}$ & $23,94 \mathrm{a}$ & $32,74 \mathrm{a}$ & $7,79 \mathrm{~b}$ \\
\hline $12 \mathrm{M}$ & $12,21 \mathrm{a}$ & $92 \mathrm{a}$ & $15,59 \mathrm{~b}$ & $70 \mathrm{c}$ & $18,67 \mathrm{~b}$ & $23,96 \mathrm{~b}$ & $9,10 \mathrm{a}$ \\
\hline $13 \mathrm{M}$ & $13,71 \mathrm{a}$ & $72 b$ & $17,75 \mathrm{~b}$ & $89 a$ & $30,58 \mathrm{a}$ & $44,47 \mathrm{a}$ & $7,20 \mathrm{~b}$ \\
\hline $14 \mathrm{M}$ & $16,79 \mathrm{a}$ & $74 a$ & $18,75 \mathrm{~b}$ & $89 a$ & 28,82 a & $32,84 \mathrm{a}$ & $7,82 \mathrm{~b}$ \\
\hline $15 \mathrm{M}$ & $19,20 \mathrm{a}$ & $100 \mathrm{a}$ & $16,0 \mathrm{~b}$ & $79 \mathrm{c}$ & $17,09 \mathrm{~b}$ & $22,43 \mathrm{~b}$ & $9,82 \mathrm{a}$ \\
\hline $16 \mathrm{M}$ & $14,62 \mathrm{a}$ & $91 \mathrm{a}$ & $13,88 \mathrm{c}$ & $60 \mathrm{c}$ & $17,12 \mathrm{~b}$ & $22,59 \mathrm{~b}$ & $9,02 \mathrm{a}$ \\
\hline $17 \mathrm{M}$ & $14,58 \mathrm{a}$ & $91 \mathrm{a}$ & $17,63 \mathrm{~b}$ & $77 \mathrm{c}$ & $18,37 \mathrm{~b}$ & $26,60 \mathrm{~b}$ & $9,13 \mathrm{a}$ \\
\hline $18 \mathrm{M}$ & $16,63 \mathrm{a}$ & $81 \mathrm{a}$ & $16,83 \mathrm{a}$ & $97 \mathrm{a}$ & $16,41 \mathrm{~b}$ & $23,04 \mathrm{~b}$ & $8,97 \mathrm{a}$ \\
\hline $19 \mathrm{M}$ & $9,58 \mathrm{~b}$ & $75 \mathrm{~b}$ & $17,21 \mathrm{~b}$ & $87 \mathrm{a}$ & $33,84 \mathrm{a}$ & $46,32 \mathrm{a}$ & $7,75 \mathrm{~b}$ \\
\hline $20 \mathrm{M}$ & $14,0 \mathrm{a}$ & $84 \mathrm{a}$ & $14,58 \mathrm{c}$ & $75 \mathrm{c}$ & $11,27 \mathrm{~b}$ & $28,62 \mathrm{~b}$ & $8,64 \mathrm{a}$ \\
\hline $21 \mathrm{M}$ & $13,0 \mathrm{a}$ & $97 \mathrm{a}$ & $17,25 \mathrm{~b}$ & $91 \mathrm{a}$ & $10,14 \mathrm{~b}$ & $28,56 \mathrm{~b}$ & $9,30 \mathrm{a}$ \\
\hline $22 \mathrm{M}$ & $15,25 \mathrm{a}$ & $77 \mathrm{~b}$ & $15,88 \mathrm{c}$ & $83 \mathrm{~b}$ & $26,85 \mathrm{a}$ & $29,69 \mathrm{a}$ & $7,89 \mathrm{~b}$ \\
\hline $23 \mathrm{M}$ & $15,08 \mathrm{a}$ & $75 \mathrm{~b}$ & $17,50 \mathrm{~b}$ & $81 \mathrm{~b}$ & $18,46 \mathrm{~b}$ & $33,24 \mathrm{a}$ & $7,85 \mathrm{~b}$ \\
\hline
\end{tabular}




\begin{tabular}{|c|c|c|c|c|c|c|c|}
\hline Matrizes & IVG & GERM & IVG-ENV & GERM-ENV & COND $2 \mathrm{~h}$ & COND $4 \mathrm{~h}$ & $\begin{array}{l}\text { Teor de } \\
\text { água\% }\end{array}$ \\
\hline $24 \mathrm{M}$ & $14,46 \mathrm{a}$ & $96 \mathrm{a}$ & $20,58 \mathrm{a}$ & $93 a$ & $10,22 \mathrm{~b}$ & $13,41 \mathrm{~b}$ & $9,18 \mathrm{a}$ \\
\hline $25 \mathrm{M}$ & $14,75 \mathrm{a}$ & $76 \mathrm{~b}$ & $15,58 \mathrm{c}$ & $82 \mathrm{~b}$ & $31,27 \mathrm{a}$ & $39,20 \mathrm{a}$ & $7,88 \mathrm{~b}$ \\
\hline $26 \mathrm{M}$ & $12,63 \mathrm{~b}$ & $90 \mathrm{a}$ & $13,42 \mathrm{c}$ & $59 \mathrm{c}$ & $16,85 \mathrm{~b}$ & $45,86 \mathrm{a}$ & $9,00 \mathrm{a}$ \\
\hline $27 \mathrm{M}$ & $16,04 \mathrm{a}$ & $74 \mathrm{~b}$ & $19,0 \mathrm{a}$ & $85 \mathrm{a}$ & $24,10 \mathrm{a}$ & $23,56 \mathrm{~b}$ & $7,78 \mathrm{~b}$ \\
\hline $28 \mathrm{M}$ & $17,13 \mathrm{a}$ & $81 \mathrm{a}$ & $18,63 \mathrm{~b}$ & $88 \mathrm{a}$ & $15,78 \mathrm{~b}$ & $18,91 \mathrm{a}$ & 8,76 a \\
\hline $29 \mathrm{M}$ & $10,67 \mathrm{~b}$ & $71 \mathrm{~b}$ & $19,71 \mathrm{a}$ & $91 \mathrm{a}$ & $23,76 \mathrm{a}$ & $29,86 \mathrm{a}$ & $7,90 \mathrm{~b}$ \\
\hline $30 \mathrm{M}$ & $11,42 b$ & $80 \mathrm{a}$ & $19,67 \mathrm{a}$ & $88 \mathrm{a}$ & $18,27 \mathrm{a}$ & $23,56 \mathrm{a}$ & $8,85 \mathrm{a}$ \\
\hline $\mathrm{CV}$ & 18,41 & 11,45 & 11,69 & 9,28 & 37,16 & 34,73 & 8,18 \\
\hline
\end{tabular}

*Médias seguidas pela mesma letra, nas colunas, não diferem entre si pelo teste de Skott-Knott em nível de 5\% de probabilidade. Legenda Porcentagem de Germinação = GERM; Índice de Velocidade de Germinação = IVG, Teste de Condutividade Elétrica = COND e Teste de Envelhecimento Acelerado (ENV). Fonte: Autores.

Com base na magnitude relativa de valores de $\mathrm{D}^{2}$, verifica-se por meio do método de Otimização de Tocher que houve a formação de seis grupos distintos, sendo os grupos V e VI formados por apenas um acesso cada: pelas matrizes 25 e 2 respectivamente. O grupo I reuniu o maior número de acessos, sendo constituído por 20 matrizes pertencentes. Os grupos II e III foram formados por três matrizes cada e o grupo IV formado por dois acessos, sendo constituído pelas matrizes 16 e 26. (Tabela 2).

Tabela 2 - Agrupamento pelo método de otimização de Tocher, com base na distância Euclidiana média, estimada a partir de 6 grupos das 30 matrizes de Parkia pendula.

\begin{tabular}{lc}
\hline GRUPOS & MATRIZES \\
\hline I & $14,23,28,15,22,27,10,24,30,13,9,6,7,11,29,3,20,8,12,1$ \\
II & $4,5,18$ \\
III & $17,21,19$ \\
IV & 16,26 \\
V & 25 \\
VI & 2 \\
\hline
\end{tabular}

Fonte: Autores.

Essa técnica de agrupamento proporcionou separar as matrizes de Parkia pendula baseados em características fisiológicas das sementes com um bom grau de divergência. Nota-se que no I grupo o número de matrizes foi maior, por apresentarem as melhores características fisiológicas.

Com a aplicação do método UPGMA, utilizando 7 variáveis quantitativas em 30 matrizes de Parkia pendula, foi gerado o dendrograma onde na análise observou-se 5 grupos distintos, o ponto de corte $80 \%$ foi estabelecido no local de ocorrência da mudança abrupta nas ramificações (Figura 2). O grupo I - matrizes 14, 23, 28, 15, 22 e 25 . Nele estão alocadas matrizes que apresentarem maiores valores em respostas ao índice de velocidade de germinação, mas não respostas semelhantes ao teste de germinação, todavia apresentaram resultados semelhantes para porcentagem de IVG do envelhecimento acelerado. 
O grupo II foi representado pelo maior número de matrizes $(10,24,11,30,07,09,06,03,01,19,08,20,17,21,13$, 27 e 29) (Figura 2). Esse grupo apresentou aproximado para as variáveis relacionadas ao IVG, a porcentagem de germinação, ao envelhecimento acelerado e com o vigor da semente, exceto para os valores de condutividade elétrica (Tabela 1).

O grupo III alocou a matrizes 4, 5 e 18. Esse grupo apresentou resultados satisfatórios para a variável de porcentagem de germinação após o envelhecimento acelerado (Figura 2 e Tabela 1). O grupo IV alocou a matriz 12 a matriz 26, sendo semelhantes ao método de Tocher e aos valores maiores de condutividade elétrica, aos valores maiores de índice de velocidade de germinação e porcentagem de germinação das sementes. A matriz 2 formou um grupo à parte (Grupo V), se une as demais matrizes no dendograma em $100 \%$, portanto esta matriz 2 é próxima igualmente para todos as matrizes de Parkia pendula.

Figura 2 - Dendrograma representativo da divergência genética entre 30 matrizes de Parkia pendula, obtido pelo método de agrupamento Hierárquico UPGMA com base em sete variáveis de sementes. (Coeficiente de correlação cofenética=0,72).

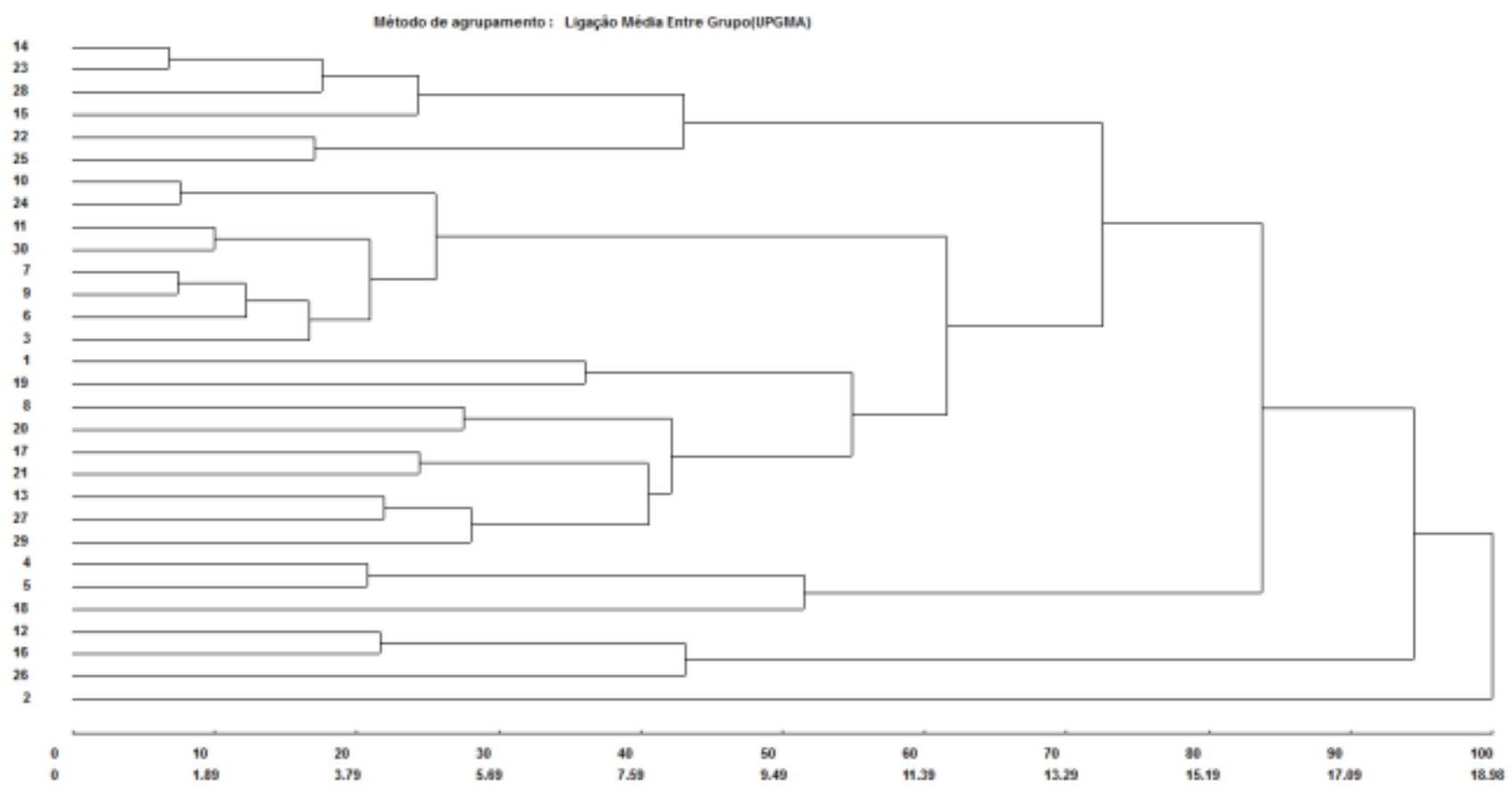

Fonte: Autores.

Em relação à contribuição relativa dos caracteres para a diversidade genética entre as matrizes estudadas (Tabela 3), com base no critério apresentado por Singh (1981), observou-se que para as 30 matrizes de Parkia pendula, têm-se em ordem crescente de contribuição, as seguintes características: porcentagem de germinação no envelhecimento acelerado, índice de velocidade de germinação (teste de germinação), índice de velocidade de germinação no envelhecimento acelerado, porcentagem de germinação (teste de germinação), condutividade elétrica em 2 horas, condutividade elétrica 4 horas e teor da água, onde verificou-se que o índice de velocidade de germinação, porcentagem de germinação e índice de velocidade de germinação do envelhecimento acelerado, contribuíram com 84,77\% da distribuição total, sendo apontadas as mais importantes no presente estudo.

Em estudos com Dinizia excelsa, Moneja (2017) aponta características que apresentem alta variabilidade ou que são altamente correlacionadas com outras, podem ser apresentadas em estudos de diversidade genética. Já Bispo em pesquisas com Anadenanthera colubrina (2017) registrou uma maior contribuição da variável de porcentagem de germinação, contribuindo para estudos de diversidade genética utilizando o método de Singh. 
$\mathrm{Na}$ análise dos resultados do método de Singh (1981) as características com maiores contribuições relativas para a análise da diversidade das matrizes foram as de porcentagem de germinação do envelhecimento acelerado (86,63\%), Índice de velocidade de germinação após envelhecimento acelerado (84,77\%), porcentagem de germinação $(69,41 \%)$ e índice de velocidade de germinação $(43,22 \%)$.

Tabela 3 - Importância relativa de sete características quantitativas para sementes avaliadas em 30 matrizes de Parkia pendula obtidas pelo método Singh (1981).

\begin{tabular}{lcc}
\hline \multicolumn{1}{c}{ Variável } & Valor (\%) & Valor Acumulado (\%) \\
\hline Índice de velocidade de germinação & 20,41 & 43,22 \\
Porcentagem de germinação & 19,31 & 69,41 \\
Índice de velocidade de germinação do EA & 16,71 & 84,77 \\
Porcentagem de germinação após EA & 9,66 & 86,63 \\
Condutividade elétrica 2H & 7,39 & 97,16 \\
Condutividade elétrica 4H & 4,55 & 99 \\
Teor da água & 1,94 & 100 \\
\hline
\end{tabular}

Fonte: Autores.

As variáveis, Teor da água, condutividade elétrica nos dois períodos, apresentaram as menores estimativas de contribuição, não se revelando importantes para a avaliação da divergência geral entre as 30 matrizes de Parkia pendula.

Após as análises de agrupamento do Tocher e UPGMA, processou-se a técnica de Variáveis Canônicas. De um modo geral, quando se trabalha com diversidade genética, pretende-se estimar a similaridade ou diferença entre o material em estudo, portanto, quando se verifica a diversidade genética pelo método das Variáveis Canônicas (VC), tem-se como propósito a identificação de matrizes similares em gráficos de dispersão bi ou tridimensional, possibilitando simplificar a interpretação dos resultados. A viabilidade de sua interpretação está restrita à concentração da variabilidade entre as primeiras variáveis, geralmente acima de $80 \%$ (Cruz et al., 2004).

Ao analisar os resultados obtidos nesse trabalho (Tabela 4) verificou-se que as quatro primeiras variáveis canônicas explicaram $83,53 \%$ da variância total acumulada, sendo $\mathrm{VC}_{1}$ responsável por $27,69 \%, \mathrm{VC}_{2}$ por $52,07 \%$ e $\mathrm{VC}_{3}$ por $81,37 \%$.

Observa-se que índice de velocidade de germinação $(27,69)$, porcentagem de germinação $(24,38)$ e índice de velocidade de germinação após o envelhecimento acelerado $(19,29)$ como sendo os caracteres que mais contribuíram para a divergência genética das matrizes de Parkia pendula estudados, pelo método de Variáveis Canônicas. Entretanto os que menos contribuíram foram teor da água $(3,67)$ e condutividade elétrica nos dois períodos $(4,81)$ para 4 horas e $(7,96)$ para 2 horas de embebição (Tabela 4). 
Tabela 4 - Estimativas dos autovalores (Ki), da variação acumulada (\%) e da importância relativa dos caracteres, explicados pelas Variáveis Canônicas (VCi).

\begin{tabular}{cccc}
\hline $\mathrm{VC}_{\mathrm{i}}$ & $\kappa_{\mathrm{i}}$ & $\begin{array}{c}\% \\
\text { acumulada }\end{array}$ & Importância dos caracteres nos autovetores \\
\hline $\mathrm{VC}_{1}$ & 27,69 & 27,69 & Índice de velocidade de germinação \\
$\mathrm{VC}_{2}$ & 24,38 & 52,07 & Porcentagem de germinação \\
$\mathrm{VC}_{3}$ & 19,29 & 81,37 & ÍVG após Env. Acelerado \\
$\mathrm{VC}_{4}$ & 12,16 & 83,53 & Porcentagem de germinação do env. \\
$\mathrm{VC}_{5}$ & 7,96 & 91,50 & Condutividade elétrica $2 \mathrm{H}$ \\
$\mathrm{VC}_{6}$ & 4,81 & 96,32 & Condutividade elétrica $4 \mathrm{H}$ \\
$\mathrm{VC}_{7}$ & 3,67 & 100 & Teor da água \\
\hline
\end{tabular}

Fonte: Autores.

Baseado nos resultados de importância relativa dos caracteres pelo método Singh e por Variáveis Canônicas, foi observado que a sequência de significância não foi similar entre os dois testes. O mesmo não ocorre com Teor de água e condutividade elétrica nos dois períodos ( 2 e 4 horas) que estão entre os três últimos caracteres em termos de importância para os dois métodos.

Vale ressaltar ainda que na análise de importância dos caracteres por meio de Variáveis Canônicas, a característica porcentagem de germinação foi a que mais contribuiu para a divergência genética das matrizes a exemplo da matriz 15 com $100 \%$ de germinação.

Cardoso e colaboradores (2009), ao trabalhar com matrizes de mamoeiro, identificaram a variabilidade genética relacionada às características de germinação da semente, que permitiu distinguir melhor as matrizes, possibilitando boas perspectivas para seleção.

Os métodos de análise de agrupamento de Tocher e de componentes principais mostraram concordância na determinação de similaridade entre as matrizes, com a formação de nove grupos distintos (Figura 3). 
Figura 3 - Gráfico de dispersão para as duas primeiras variáveis canônicas representando a formação de nove grupos das matrizes de Parkia pendula.

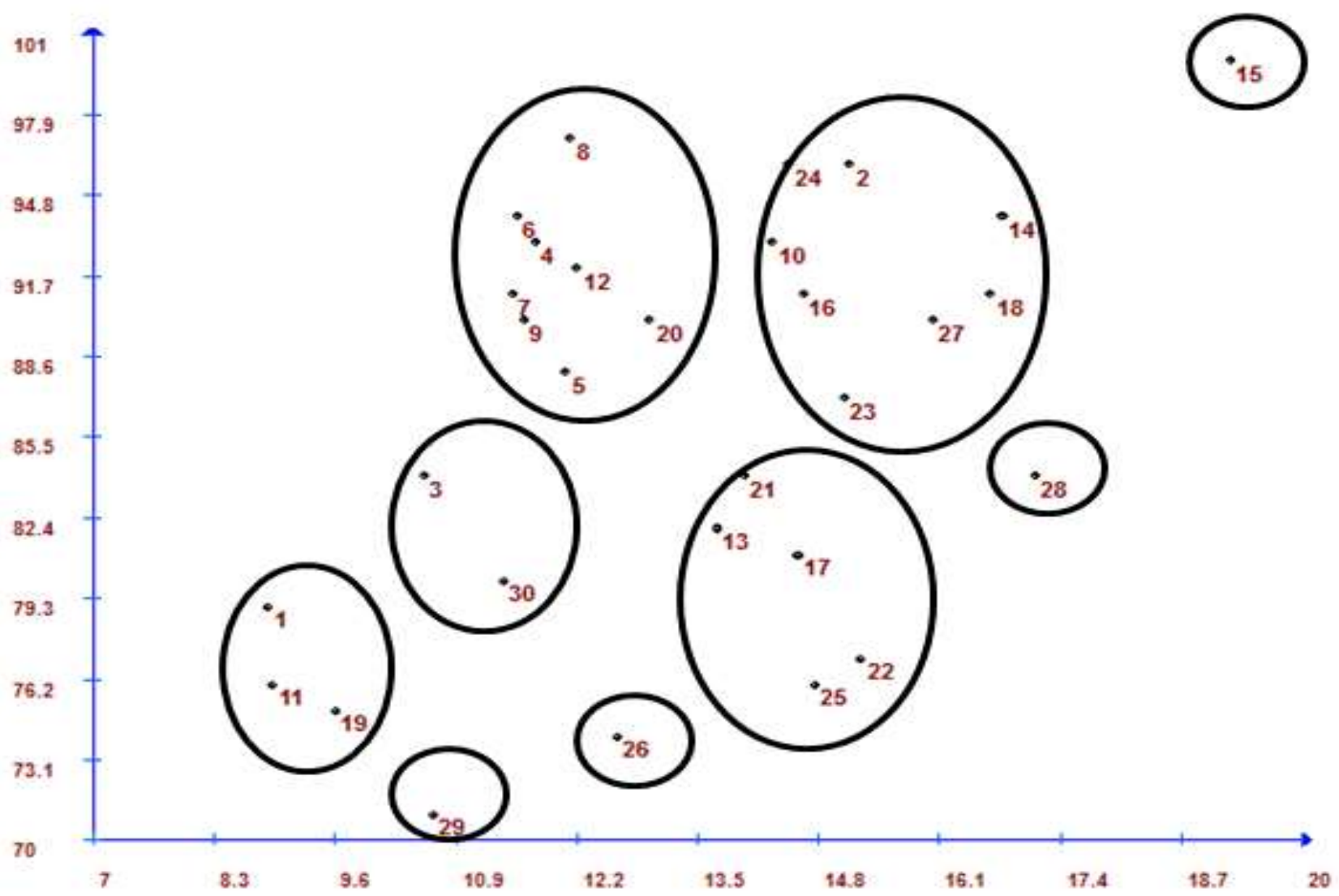

Fonte: Autores.

A matriz mais distante foi a matriz 15 que apresentou os melhores resultados para as características de semente avaliadas, alocada no grupo I. Entretanto com valores próximos a germinação e índice de velocidade de germinação, formadas pelo grupo II (matrizes 4, 5, 6, 4, 7, 8, 9, 12 e 20). As matrizes 13,17, 21, 22 e 25 apresentaram uma distribuição similar na técnica UPGMA, sendo alocados no grupo III. O grupo IV, representado pela maior quantidade de matrizes, sendo elas, 2, 10, 14, 16, 18, 23 e 24 obtiveram uma maior similaridade no índice de velocidade de germinação. No entanto, para variável de porcentagem de germinação o grupo $\mathrm{V}$, foi o melhor representado pelas matrizes, 4, 5, 6, 7, 8, 9, 12 e 20. As matrizes 26 e 28 apresentaram uma distribuição similar a maiores porcentagens de germinação, sendo alocados, respectivamente, nos grupos VI, VII e grupo VIII, composto pelas matrizes 3 e 30. O grupo IX, representado pelas matrizes 1, 11 e 19 apresentaram os menos valores para as variáveis canônicas (Figura 3).

Quando se compara os escores dos componentes principais aos agrupamentos revelados pelo algoritmo de Tocher, nota-se certa concordância entre as análises, pois, a discriminação dos grupos foi semelhante com relação aos agrupamentos. Assim, pode-se observar que a dispersão das matrizes por meio de Variáveis Canônicas demonstrou comportamento semelhante ao agrupamento do método UPGMA, contudo, vale ressaltar que foi diferente do representado pelo método de Tocher.

De acordo com os valores da matriz de dissimilaridade (Tabela 5), os acessos 1 e 2 foram os mais similares $\left(\mathrm{d}_{\mathrm{ii}} \mathrm{u}^{\circ} 0,01\right)$, enquanto que os acessos 3 e 5 os mais distantes $\left(\mathrm{d}_{\mathrm{ii}}\right.$ 2,88). Este resultado aponta ao fato de essas matrizes estarem geograficamente distantes entre si explica a maior divergência encontrada. 
Tabela 5 - Medidas de dissimilaridade entre as 30 matrizes de Parkia pendula, em relação a 7 descritores multicategóricos, com base na Distancia generalizada de Mahalanobis (D2iiec).

\begin{tabular}{cccccccc}
\hline Acesso & 1 & 2 & 3 & 4 & 5 & 6 & 7 \\
\hline 1 & 1,0 & & & & & & \\
2 & 0,01 & 1,0 & & & & & \\
3 & 0,94 & 0,0 & 1,0 & & & & \\
4 & 0,13 & 0,17 & 0,28 & 1,0 & & & \\
5 & 0,36 & 0,67 & 2,88 & 0,38 & 1,0 & & \\
6 & 0,25 & 0,97 & 0,35 & 0,52 & 1,17 & 1,0 & 0,018 \\
7 & 0,10 & 0,17 & 0,32 & 0,02 & 0,36 & 0,0 \\
\hline
\end{tabular}

Fonte: Autores.

As análises subsidiaram avaliar a existência de diversidade genética entre as 30 matrizes de Parkia pendula na Amazônia Matogrossense. Ramalho (2016) afirma que reunir conhecimentos sobre aspectos da germinação de sementes de diversas matrizes, principalmente as nativas são fundamentais para a propagação e para a manutenção de bancos de germoplasma. Contudo, Silva e colaboradores (2020), retratam que embora o volume de informações genéticas provenientes de testes para qualidade fisiológica das sementes tenha aumentado consideravelmente nos estudos de diversidade genética, continua-se a dar importância ao estudo da diversidade por meio de características fenotípicas, principalmente as de natureza quantitativa, dentre elas as características de semente que apresentam, geralmente, distribuição contínua e são determinadas por vários genes.

\section{Conclusão}

As análises das características fisiológicas das sementes apontam que existe alta divergência genética entre matrizes de Parkia pendula nativa na Amazônia mato-grossense. As características com maiores contribuições relativas para a análise da diversidade das matrizes foram as de porcentagem de germinação e índice de velocidade de germinação. A variação do Teor de água das sementes pode indicar uma plasticidade da espécie em função da área de ocorrência delas.

As análises de sementes se mostraram eficientes para estimar variabilidade genética das matrizes. A importância no interesse na avaliação dos caracteres estudados procede, na possibilidade de se descartar os que contribuem pouco para a discriminação das comunidades, reduzindo, dessa forma, mão-de-obra, tempo e custos consumidos na experimentação.

\section{Agradecimentos}

Agradecemos a Universidade do Estado de Mato Grosso - UNEMAT e ao Programa de Pós-graduação em Genética e Melhoramento de Plantas por terem nos proporcionado o desenvolvimento desta pesquisa.

\section{Referências}

Brasil. (2009). Ministério da Agricultura, Pecuária e Abastecimento. Regras para análise de sementes. Brasília: Secretaria de Defesa Agropecuária, MAPA/ACS.

Bispo, J. S., Costa, D. C. C., Gomes, S. E. V., Oliveira, G. M., Matias, J. R., Ribeiro, R. C., \& Dantas, B. F. (2017). Size and vigor of Anadenanthera colubrina (Vell.) Brenan seeds harvested in Caatinga areas. Journal of Seed Science, 39(4), 363-373.

Cardoso, D. L., Silva, R. F. da, Pereira, M. G., Viana, A. P., \& Araújo, E. F. (2009). Diversidade genética e parâmetros genéticos relacionados à qualidade fisiológica de sementes em germoplasma de mamoeiro (v.56, pp.572-579). Revista Ceres.

Carvalho, N. M., \& Nakagawa, J. (2012). Sementes: ciência, tecnologia e produção (5a ed.), 590. FUNEP. 
Research, Society and Development, v. 10, n. 5, e50410515224, 2021

(CC BY 4.0) | ISSN 2525-3409 | DOI: http://dx.doi.org/10.33448/rsd-v10i5.15224

Cruz, C. D., \& Carneiro, P. C. S. (2006). Modelos biométricos aplicados ao melhoramento genético (2a ed.), 585 . UFV.

Cruz, C. D., \& Regazzi, A. J. (2001). Modelos biométricos aplicados ao melhoramento genético (p. 390). UFV.

Cruz, C. D., Regazzi, A. J., \& Carneiro, P. C. S. (2004). Modelos biométricos aplicados ao melhoramento genético (v.1. p.480). Editora UFV.

Maguire, J. D. (1962). Seep of germination-aid seedling emergence and vigor (v.2, pp.176-177). Crop Science.

Malavasi, M. de M. (1988). Manual de análise de sementes florestais (pp.25-40). Fundação Cargil. Campinas.

Matias, U. M., Alves, E.U., Araújo, P. C., Alves, M. M., Ribeiro, T. S., \& Silva, R. S. (2019). Superação de dormência e vigor em sementes de Fava-d'Anta (Dimorphandra gardneriana tulasne). 29(1), Ciência Florestal. (01039954).

Mojena, P. A., \& Coelho, C. V. L. (2017). Evaluation of the physiological quality of Parkia platycephala seeds (v.10, n.4, and pp.20-31). Scientific Electronic Archives.

Moreira, F. M. S., \& Moreira, F. W. (1996). Características da germinação de sementes de 64 espécies de leguminosas florestais nativas da Amazônia, em condições de viveiro (v.26, pp.3-16). Acta amazônica.

Oliveira, M. C. P., \& Ferraz, I. D. K. (2003). Comportamento das sementes de Parkia pendula (Wild.) Walp. (Visgueiro) no banco de semente aéreo. In: Higuchi, N. (Org.), Projeto Jacarandá, fase II: pesquisas florestais na Amazônia Central. Manaus: Coordenação de Pesquisas em Silvicultura Tropical (p.103116). INPA.

Pieper, V. E. P. (2020). Análise dos elementos climáticos e suas influencias em área agrícola na região norte do Mato Grosso 18 (1), pp.69-82. Revista Matogrossense de Geografia.

Rodrigues, A. B. M., Giuliatti, N. M., \& Júnior, A, P. (2020). Application of methodologies for degraded areas recovering in the Brazilian Biomes (v.4, n.1, p.333-369). Brazilian Applied Science Review.

Santana, B. J. G de, Silva, J. P. G da., \& Maragon, L, Cfeliciano, A, L, P. (2018). Morfologia externa de sementes e plântulas de Parkia pendula Benth. ex Walp., (v.4, n.1-2, p.3-10). Revista Arrudea-A revista do Jardim Botânico do Recife.

Schumacher, M, V. Hoppe, J, M., \& Farias, J. A. (2002). Manual de instruções para a coleta, beneficiamento, armazenamento e análise de sementes florestais. Projeto bolsa de sementes de espécies florestais, UFSM/AFUBRA.

Singh, D. (1981). The relative importance of characters affecting genetc divergence. (v.41, pp.237-245). The Indian Journal of Genetc and Plant Breeding.

Siqueira, E. R., \& Ribeiro, F. E. (2001). Restauração florestal na região da mata atlântica de Sergipe. (pp.97-126). A Mata Atlântica de Sergipe.

Smith, M, T., Wang, B, S., \& Msanga, H, P. (2010). Dormancia y germinación. Manual de Semillas de Árboles Tropicales. Departamento de Agricultura dos (pp.157-182). Washington.

Silva, J. N., de Silva, M. A. D., Rodrigues, M. H. B. S., \& Alves, R. M. (2020). Testes de envelhecimento acelerado e condutividade elétrica para Sementes de Espécies Florestais Nativas: Uma breve revisão. 1 (2) Meio Ambiente (Brasil).

Souza Filho, A. P. S., Fonseca, M. L. \& Arruda, M. S. P. (2005). Substâncias químicas com atividades alelopáticas presentes nas folhas de Parkia pendula (Leguminosae). 23(4), (pp.565-73) Planta Daninha. 